\title{
Kinsenoside prevents ovariectomy-induced bone loss and suppresses osteoclastogenesis by regulating classical NF- $K B$ pathways
}

\author{
H.-B. Hsiao • H. Lin • J.-B. Wu • W.-C. Lin
}

Received: 5 June 2012 / Accepted: 8 October 2012 /Published online: 10 November 2012

(C) The Author(s) 2012. This article is published with open access at Springerlink.com

\begin{abstract}
Summary Kinsenoside is able to improve bone turnover rate in ovariectomized (OVX) mice. In vitro analysis shows that kinsenoside antagonizes osteoclast development and bone resorption.

Introduction Kinsenoside, the main active compound of the traditional Taiwanese herb Anoectochilus formosanus, has an antiinflammatory effect. This study investigates whether kinsenoside inhibits osteoporosis and osteoclastogenesis. Methods OVX mice were used to examine the antiosteoporotic activity of kinsenoside. The trabecular bone microarchitecture was assessed by microcomputed tomography. In vitro experiments were performed to determine the mechanisms of the antiosteoporotic effects of kinsenoside.

Results Microcomputed tomography scanning showed that kinsenoside suppresses bone loss in OVX mice. Kinsenoside decreases plasma CTx concentration. Reverse transcription polymerase chain reaction (RT-PCR) analysis also showed that kinsenoside reduces the femoral mRNA expression of tartrate-resistant acid phosphatase (TRAP) and matrix metalloproteinase-9 (MMP-9). Kinsenoside inhibits osteoclast formation in bone marrow cells (BMs) and RAW 264.7 cells. Western blot was used to analyze osteoclast-associated signaling
\end{abstract}

H.-B. Hsiao $\cdot$ H. Lin

Department of Life Sciences, National Chung Hsing University, Taichung, Taiwan

J.-B. $\mathrm{Wu}$

Graduate Institute of Pharmaceutical Chemistry,

China Medical University,

Taichung, Taiwan

W.-C. Lin $(\bowtie)$

School of Medicine, Graduate Institute of Basic Medical Science and Tsuzuki Institute for Traditional Medicine,

China Medical University,

Taichung, Taiwan

e-mail: wclin@mail.cmu.edu.tw pathways in RAW 264.7 cells. Results show that kinsenoside does not inhibit IKK phosphorylation but suppresses the phosphorylation of $I \kappa B \alpha$ and $p 65$. Kinsenoside significantly inhibits the RANKL induction of IKK activity. Kinsenoside inhibits the RANKL-triggered nuclear translocations of NF- $\mathrm{KB}$ and nuclear factor of activated T cells $\mathrm{c} 1$ (NFATc1). RT-PCR was used to analyze osteoclast precursor fusion and resorption-associated gene expression in BMs. Kinsenoside inhibits the expression of cathepsin $K(C A K)$, dendritic cell-specific transmembrane protein, MMP-9, and TRAP.

Conclusions Kinsenoside inhibits osteoclastogenesis from macrophages by attenuating RANKL-induced NF-KB and NFATc1 activities, which in turn, prevents bone loss from OVX mice.

Keyword Kinsenoside $\cdot$ Osteoclastogenesis $\cdot$ Osteoporosis

\section{Introduction}

Bone remodeling depends on the balance between bone resorption and bone formation [1]. Postmenopausal osteoporosis reflects an imbalance in bone remodeling in which osteoclastic bone resorption exceeds osteoblastic bone formation [2]. The ovariectomized (OVX) model has been used as an animal model for various clinical syndromes derived from osteoporosis [3]. The serum concentration of C-terminal telopeptides of type I collagen (CTx) and the serum activity of alkaline phosphatase (ALP) are markers of bone resorption and bone formation, respectively [4]. Previous research has shown that CTx and ALP are significantly greater in an OVX group than in a sham-operated group [4].

Osteoclasts are bone-resorbing cells derived from hematopoietic precursors in the presence of the macrophage colonystimulating factor (M-CSF) and the receptor activator of the nuclear factor- $\mathrm{kB}$ ligand (RANKL) [5]. The binding of RANKL to its receptor RANK leads to the recruitment of 
TNF receptor-associated factor 6 (TRAF6) to the cytoplasmic domain of RANK $[6,7]$. The downstream targets of TRAF6 are predominantly mediated by a trimeric complex containing the NF- $\mathrm{KB}$ essential modulator (NEMO), an inhibitor of NF$\kappa B$ kinase (IKK) $\alpha$ and IKK $\beta$. IKK regulates the degradation of the inhibitor of NF- $\kappa \mathrm{B}, \mathrm{I} \kappa \mathrm{B} \alpha$, by promoting its phosphorylation and further degradation via the proteasome-ubiquitin pathway. Liberated NF- $\mathrm{KB}$ subsequently translocates into the nucleus, where it binds to DNA and promotes the transcription of various genes [8]. NF- $\mathrm{BB}$ is important for the initial induction of the nuclear factor of activated $\mathrm{T}$ cell $\mathrm{c} 1$ (NFATc1) expression. NFATc1 binds to its own promoter, thus switching on a robust induction of NFATc1 [8]. NFATc1 is likely a key regulator of RANKL-induced osteoclast differentiation, fusion, and activation [9, 10].

Alendronate is a synthetic agent that is currently the most widely used drug for postmenopausal osteoporosis. Alendronate is a bone resorption inhibitor that maintains bone mass by inhibiting the function of osteoclasts [11]. Some people taking alendronate have experienced severe effects, such as osteonecrosis and insufficiency fractures [12, 13]. Growing evidence shows that the benefits of natural products, which are thought to be healthier and safer for the treatment of osteoporosis, can overcome the side effects of this synthetic drug.

Kinsenoside [3-(R)-3- $\beta$-D-glucopyranosyloxybutanolide] is a significant and active compound of the Anoectochilus formosanus (Orchidaceae), an important ethnomedicinal plant in Taiwan [14]. This compound has hepatoprotective, hypoglycemic, and antiinflammatory effects [15-17]. Kinsenoside inhibits NF-KB activation by lipopolysaccharide (LPS) in mouse peritoneal lavage macrophages (MPLMs) [17]. Several reports have shown that crude extracts of $A$. formosanus can ameliorate the osteoporosis induced by ovariectomy in rats $[18,19]$. However, the antiosteoporotic activity of kinsenoside remains unclear.

This study investigates the effects of kinsenoside on osteopenia in OVX mice, using alendronate as a positive control drug. In vivo study indicates that the antiosteoporotic activity of kinsenoside might be related to its inhibitory effect on osteoclastogenesis. This study also investigates the effects of kinsenoside on RANKL-induced NF- $k$ B activation and on osteoclastogenesis in osteoclast precursor cells.

\section{Materials and methods}

\section{Preparation of kinsenoside}

Kinsenoside was prepared by Professor $\mathrm{Wu}$. The identity and purity of kinsenoside ( $>85 \%$ ) were analyzed by HPLC according to a previous report [15]. For the in vivo study, kinsenoside was dissolved in distilled water and concentrations of 10 and $30 \mathrm{mg} / \mathrm{ml}$ were prepared.
Animals

Female Wistar rats and imprinting control region (ICR) mice were purchased from BioLASCO Co., Ltd. (Taipei, Taiwan). The experimental animals received humane care, and the study protocols complied well with the institutional guidelines of the China Medical University for the use of laboratory animals. The animals were housed in an air-conditioned room (21-24 $\left.{ }^{\circ} \mathrm{C}\right)$ under $12 \mathrm{~h}$ of light (7:00-19:00) and were allowed free access to food pellets and water throughout the study.

Animal experiments

Female mice were anesthetized with sodium pentobarbital (40 mg/kg, i.p.) for the bilateral removal of the ovaries. The mice in the sham-operated group were anesthetized, laparotomized, and sutured without removal of the ovaries. After 3 days of recovery from surgery, the OVX mice were randomly divided into four groups and orally treated with vehicle $\left(\mathrm{H}_{2} \mathrm{O}\right)$, kinsenoside (100 and $300 \mathrm{mg} / \mathrm{kg}$ daily), or alendronate $(2.5 \mathrm{mg} / \mathrm{kg}$ every other day; Sigma-Aldrich, St. Louis, MO, USA) for 4 weeks. The sham-operated group was orally treated with $\mathrm{H}_{2} \mathrm{O}$ only.

Plasma ALP levels were measured using clinical kits (Roche Diagnostics, Mannheim, Germany) and a spectrophotometric system (Cobas Mira; Roche, Rotkreuz, Switzerland). Plasma CTx levels were determined using a mouse-specific enzyme-linked immunosorbent assay (ELISA) according to the manufacturer's protocols (Nordic Bioscience Diagnostics, Herlev Hovedgade, Denmark).

Microtomography analysis was performed as reported previously [20]. The trabecular bone microarchitecture of the distal right femoral metaphysis was measured using a microtomography scanner (SkyScan 1076, Kontizh, Belgium), with an isotropic resolution of $18 \mu \mathrm{m}$ in all three spatial dimensions. Bone volume and tissue volume were measured directly from the original three-dimensional images, and trabecular bone volume (bone volume/tissue volume, percent) was calculated by dividing the bone volume by the total volume of interest. Other parameters of trabecular structure were studied, including thickness, separation, and the number of trabeculae, as calculated directly from three-dimensional images.

The left femur was removed, fixed with $4 \%$ neutralbuffered paraformaldehyde in phosphate-buffered saline (PBS; pH 7.4) for $48 \mathrm{~h}$, and decalcified in $10 \%$ ethylenediamine tetraacetic acid solution ( $\mathrm{pH} 7.4$ ) at $4{ }^{\circ} \mathrm{C}$ for 4 weeks. After decalcification, each bone sample was cut along the coronal plane, embedded in paraffin, and cut longitudinally into sections for histological staining. For measurement of the osteoclast number, sections were stained for tartrate-resistant acid phosphatase (TRAP) with TRAP kit (Sigma-Aldrich, St. Louis, MO, USA) as previously described [21]. 
To explore the mechanisms associated with kinsenoside on OVX-induced osteoporosis in mice, total RNA of the right tibiae was extracted for analysis of RT-PCR. The expression levels of ALP, matrix metalloproteinase-9 (MMP9), and TRAP were normalized to that of GAPDH mRNA in the same tissue. The PCR products were separated on a $2 \%$ agarose gel and recorded on Polaroid film; the band was quantified with a densitometer. The mean ratio of each group was calculated as the average for eight animals. The fragments shown in Fig. 2e reflect the pooled data for eight samples.

Osteoclast differentiation of bone marrow cells

Bone marrow cells (BMs) were prepared by removing bone marrow from the femora and tibiae of Wistar rats weighing $220-250 \mathrm{~g}$ and then flushing the bone marrow cavity with $\alpha$ MEM (Hyclone, Logan, UT, USA) supplemented with $20 \mathrm{mM}$ HEPES, $10 \%$ heat-inactivated fetal bovine serum (FBS), $2 \mathrm{mM}$ glutamine, penicillin $\left(100 \mathrm{U} \mathrm{ml}^{-1}\right)$, and streptomycin $\left(100 \mathrm{\mu gml}^{-1}\right)$. The nonadherent cells (hematopoietic cells) were collected after $24 \mathrm{~h}$ and used as osteoclast precursors. Cells were seeded in $1 \times 10^{6}$ cells/well in 24 -well plates in the presence of RANKL (50 $\mathrm{ngml}^{-1}$; PeproTech EC, London, UK) and M-CSF (20 ngml ${ }^{-1}$; PeproTech EC). Cells were treated with kinsenoside based on findings that MPLMs do not undergo any change in viability after exposure to LPS+ kinsenoside. In addition, kinsenoside $\left(\mathrm{IC}_{50}, 50 \mu \mathrm{M}\right)$ inhibits the LPS-induced production of IL- $1 \beta$. Various concentrations of kinsenoside $(10,25$, and $50 \mu \mathrm{M})$ were added to these cultures for 9 days. The culture medium was replaced with fresh medium every 3 days. Osteoclast formation was measured using the TRAP staining kit on day 9 [21]. Briefly, adherent cells were fixed with $10 \%$ formaldehyde in PBS for $3 \mathrm{~min}$ and then stained with naphthol AS-Mx phosphate and tartrate solution for $1 \mathrm{~h}$ at $37^{\circ} \mathrm{C}$. TRAP-positive cells with more than three nuclei were scored as osteoclasts [22]. The viability of the BMs was detected by MTS assay (CellTiter 96 AQueous One Solution Cell Proliferation Assay, Promega Corporation, Madison, WI, USA).

\section{Osteoclast differentiation of RAW 264.7 cells}

RAW 264.7 cells, which are derived from murine macrophages and obtained from the Food Industry Research and Development Institute (Hsinchu, Taiwan), were cultured in dulbecco's modified eagle medium (DMEM) (Hyclone Logan, UT, USA) supplemented with $10 \% \mathrm{FBS}, 100 \mathrm{U} / \mathrm{ml}$ of penicillin, and $100 \mu \mathrm{g} / \mathrm{ml}$ of streptomycin. For differentiation of osteoclasts, RAW 264.7 cells $\left(1 \times 10^{3}\right.$, in a 24 -well plate) were cultured in the presence of the RANKL $(50 \mathrm{ng} / \mathrm{ml})$ for 5 days. The culture medium was replaced every 3 days. Various concentrations of kinsenoside $(10,25$, and $50 \mu \mathrm{M})$ were added to these cultures. Osteoclast formation was measured using a TRAP staining kit. The viability of RAW 264.7 cells was also detected by the MTS assay.

Resorption pit assay

RAW264.7 cells were plated on BD BioCoat ${ }^{\mathrm{TM}}$ Osteologic ${ }^{\mathrm{TM}}$ at a density of 2,000 cells/well in a 96-well tissue culture plate, and incubated with different concentrations of kinsenoside $(10,25$, and $50 \mu \mathrm{M})$ in the presence of RANKL $(50 \mathrm{ng} / \mathrm{ml})$ for 7 days. The culture medium was replaced with fresh medium containing these stimuli every 3 days. After the culture, the slices were rinsed with PBS and left overnight in $1 \mathrm{M}$ ammonium hydroxide to remove attached cells. Resorption pits on $\mathrm{BD}$ BioCoat ${ }^{\mathrm{TM}}$ Osteologic ${ }^{\mathrm{TM}}$ were counted using the Image Pro-plus program (v. 4.0).

\section{Electrophoretic mobility shift assay}

To determine NF- $\mathrm{KB}$ activation, the sequencing of the NFkB-binding oligonucleotide used a cy5.5-5'-AGCTTGGGGACTTTCCGA-3' DNA probe (Bio-Protech, Taipei, Taiwan) as fluorescence. Nuclear protein extracts from RAW 264.7 cells were prepared following the method of Chen et al. [23]. The DNA binding reaction with nuclear protein was performed at room temperature in a volume of $20 \mu \mathrm{l}$, which contained the binding buffer $(10 \mathrm{mM}$ Tris- $\mathrm{HCl}, \mathrm{pH} 7.5$, $50 \mathrm{mM} \mathrm{NaCl}, 1 \mathrm{mM}$ dithiothreitol (DTT)), $1 \mu \mathrm{g}$ of poly (dI-dC), $50 \mathrm{nM}$ cy5.5-labeled probe, $0.5 \%$ Tween 20 , and $15 \mu \mathrm{g}$ of nuclear extracts. After incubation for $30 \mathrm{~min}$, the samples were electrophoresized on native $5 \%$ acrylamide gels prepared in a $0.5 \times$ TBE buffer (AMRESCO, Solon, OH, USA). Supershift assays using anti-p65 and anti-p50 antibody were also conducted to confirm the specificity of NF-KB DNA-binding activity. "Cold" represents a nuclear extract preincubated with an excess of unlabeled oligonucleotide. The gel was subsequently imaged with a LI-COR Odyssey Infrared Imaging System (LI COR Biosciences, Lincoln, NE, USA) in 700-nm channels with a $169 \mu \mathrm{m}$ resolution. The density of fluorescence in each band was measured in triplicate using LI-COR imaging software.

Immunofluorescent staining

Effects of kinsenoside on the nuclear translocation of p65 were examined by immunofluorescence, as described previously [24]. Briefly, $5 \times 10^{4}$ RAW 264.7 cells were seeded onto a 24-well plate preseeded with coverslips. After overnight incubation to allow for cell attachment, the cells were preincubated with kinsenoside $(10,25$, and $50 \mu \mathrm{M})$ for $2 \mathrm{~h}$ before stimulation for $1 \mathrm{~h}$ with RANKL $(50 \mathrm{ng} / \mathrm{ml})$. After incubation, cells were washed twice with $1 \times \mathrm{PBS}$, fixed for $15 \mathrm{~min}$ at room temperature with $4 \%$ paraformaldehyde in $1 \times \operatorname{PBS}(\mathrm{pH} 7.4)$, and then washed extensively with $1 \times$ 
PBS. Cells were then permeabilized in $1 \times$ PBS containing $0.1 \%$ Triton X-100. After blocking with $0.1 \%$ BSA-PBS, cells were incubated at $4{ }^{\circ} \mathrm{C}$ overnight with anti-p65 antibody (Cell Signaling, Danvers, MA, USA) diluted 1:200 in PBS. Cells were then labeled for $1 \mathrm{~h}$ at room temperature with an Alexa Fluor 488 phallotoxin (Molecular Probes, Inc., Eugene, OR, USA) diluted 1:500 in PBS. Cells were then washed in PBS as before, counterstained for $3 \mathrm{~min}$ at room temperature with 4'-6-diamidino-2-phenylindole (DAPI) (Santa Cruz Biotechnology, Inc., CA, USA), and mounted for confocal microscopy (Leica TCS SP2, Buffalo Grove, IL, USA).

\section{Luciferase assay}

To examine NF-kB activation, RAW 264.7 cells $\left(5 \times 10^{4}\right.$ in $1 \mathrm{ml}$ of fresh medium) were seeded in a 24-well plate before transfection. The NF- $\mathrm{kB}$ luciferase reporter plasmids and pRL-TK used in this study were obtained from Promega (Madison, WI, USA). The DNA/jetPEI ${ }^{\circledR}$-Macrophage mixture was then added to the cells. The cells were incubated in a humid atmosphere of $5 \% \mathrm{CO}_{2}$ at $37^{\circ} \mathrm{C}$ for $6 \mathrm{~h}$. After $6 \mathrm{~h}$, the transfected cells were treated with kinsenoside for $120 \mathrm{~min}$ and then stimulated with RANKL $(50 \mathrm{ng} / \mathrm{ml})$ for $24 \mathrm{~h}$. The cell lysates were then used for the luciferase assay. Luciferase activity was measured using a Promega Luciferase Assay System (Promega). The activity was measured using a Fluoroskan ${ }^{\circledR}$ Ascent FL (Thermo Fisher Scientific, Rochester, NY, USA). The cells were cotransfected with pRL-TK as an internal control to normalize the reporter gene activity and ensure the expression of luciferase in all subsequent experiments.

\section{Western blot analysis}

RAW 264.7 cells were incubated with or without RANKL in the presence or absence of kinsenoside. The extraction of cytoplasmic and nuclear proteins was performed as described previously [24]. The primary antibodies were obtained from the following sources: p65, phosphorylated p65 (p-p65), $\operatorname{I\kappa } B \alpha$, phosphorylated I $\operatorname{B} \alpha(\mathrm{p}-\mathrm{I} \kappa \mathrm{B} \alpha), \operatorname{IKK} \alpha, \operatorname{IKK} \beta$, and phosphorylated IKK $\alpha / \beta(p-I K K \alpha / \beta)$ from Cell Signaling (Danvers, MA, USA), and proliferating cell nuclear antigen (PCNA), $\alpha$-tubulin, p50, and NFATc1 from Santa Cruz (CA, USA). The whole-protein extracts prepared following the method described by Lee et al. were used for the Western blot analysis of NFATc1 expression [25]. Western blot analysis was performed as described previously [17].

\section{IKK activity assay}

IKK activity was measured by an IKK $\alpha$ KinEASETM FP Fluorescein Green Assay Kit (Millipore, Billerica, MA, USA) following the manufacturer's instructions. A fluorescence polarization assay was performed using a Synergy 2 fluorescence plate reader (BioTek Instruments, Inc., USA) with excitation set at $485 \mathrm{~nm}$ and emission at $530 \mathrm{~nm}$.

\section{RT-PCR analysis}

The BMs were cultured for 3 days in the presence of M-CSF $(20 \mathrm{ng} / \mathrm{ml})$. Adherent cells were used as osteoclast precursors. To generate osteoclasts, osteoclast precursors were cultured with M-CSF $(20 \mathrm{ng} / \mathrm{ml})$ and RANKL $(50 \mathrm{ng} / \mathrm{ml})$ for 3 days in the presence of kinsenoside. Total RNA was extracted with TRIzol (Invitrogen, Carlsbad, CA, USA) following the manufacturer's instructions. The PCR primer sequences for mouse $A L P$, cathepsin $K(C A K)$, dendritic cell-specific transmembrane protein (DC-STAMP), MMP9, RANK, TRAF6, and TRAP were as follows: primers for $A L P$ were $5^{\prime}$-GTATGCCTCCTGCATTGGGG-3' (sense) and $5^{\prime}$-TGTTCCTGCTGGAAGTTGCC-3' (antisense); primers for $C A K$ were $5^{\prime}$-CTGCCCATAACCTGGAGG-3' (sense) and 5'-GCCCTGGTTCTTGACTGG-3' (antisense); primers for DC-STAMP were 5'-ACCCGTTGCCCT GCTCTCTT-3' (sense) and 5'-ACGGAGGCCACACGA CAGAA-3' (antisense); primers for GAPDH were 5'CTTCATTGACCTCAACTACATGGTCTA-3' (sense) and 5'-GATGACAAGCTTCCCATTCTCAG-3' (antisense); primers for MMP-9 were 5'-GGTCTAGGCCCAGAGGTA-3' (sense) and 5'-GGTCGTAGGTCACGTAGC-3' (antisense); primers for RANK were $5^{\prime}$-GTGACTCTCCAGGTCAC TCC-3' (sense) and 5'-GGCAGACACACACTGTCG-3' (antisense); primers for TRAF6 were 5'-GTTCTCAGG GAGCCCTAC-3' (sense) and 5'-GAGGCACAGCTAAGGGAC-3' (antisense); primers for TRAP were 5'-GAACCGT GCAGACGATGG-3' (sense) and 5'-GGAAGTTC CAGCGCTTGG-3' (antisense). The expected sizes of PCR products were $232 \mathrm{bp}$ for ALP, $230 \mathrm{bp}$ for CAK, $109 \mathrm{bp}$ for DC-STAMP, $99 \mathrm{bp}$ for GAPDH, $310 \mathrm{bp}$ for MMP-9, 134 bp for RANK, 364 bp for TRAF6, and $231 \mathrm{bp}$ for TRAP. All primer sets were designed using NCBI/Primer-BLAST.

Statistical analysis

This study expresses results as the mean $\pm \mathrm{SD}$. All experimental data were analyzed by one-way analysis of variance

Fig. 1 Microtomography analysis of metaphysic of the distal femurs in OVX mice of different groups. a Representative sample from each group: 3D architecture of trabecular bone within the distal femoral metaphyseal region. Effects of kinsenoside and alendronate on the trabecular bone volume (b), thickness of the trabeculae (c), number of trabeculae (d), and separation of trabeculae (e) of the distal femoral metaphysic in OVX rats by microtomography analysis. Values are means $\pm \mathrm{SD}(n=8)$. Values not sharing a common superscript differ significantly. Ale alendronate, $B V / T V$ bone volume/tissue volume, $T b . T h$ thickness of the trabeculae, Tb.N number of trabeculae, $T b . S p$ separation of trabeculae 


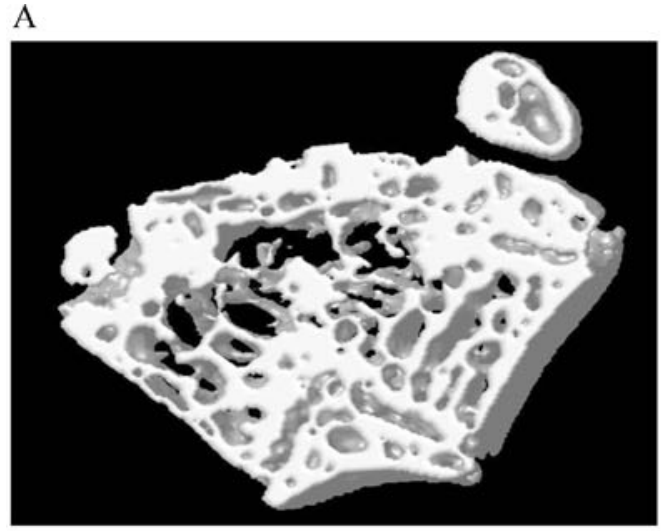

Sham

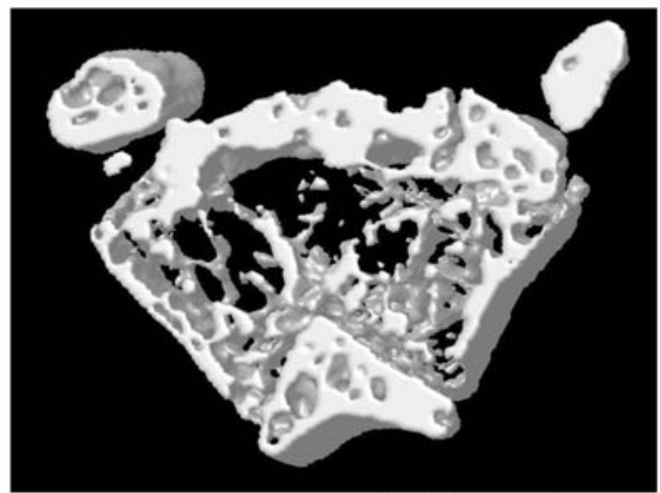

OVX + Kinsenoside 300 mg/kg
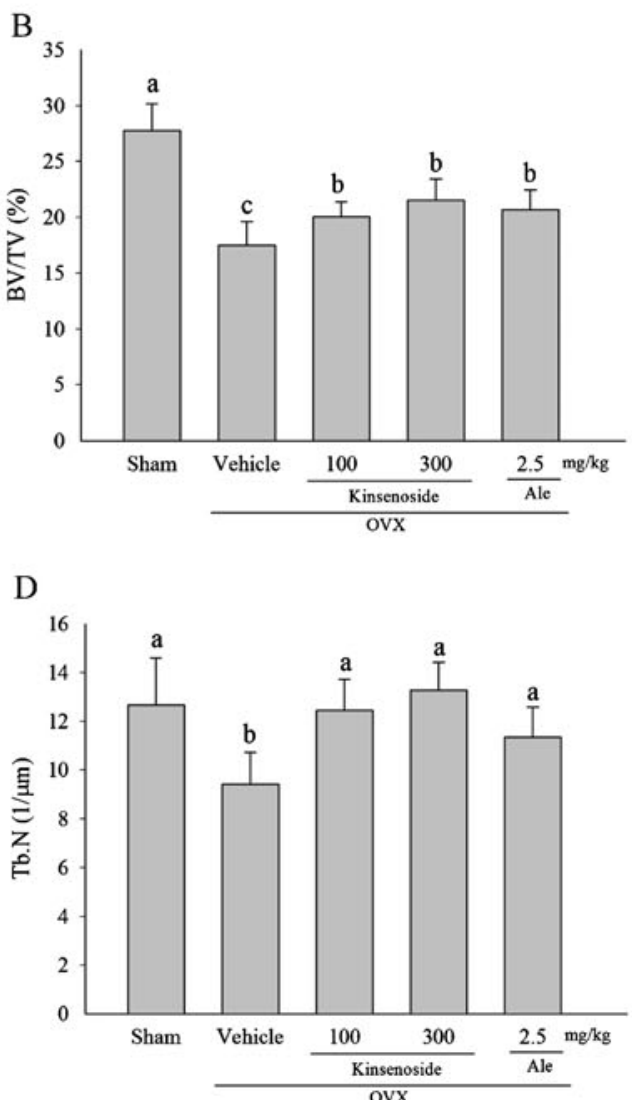

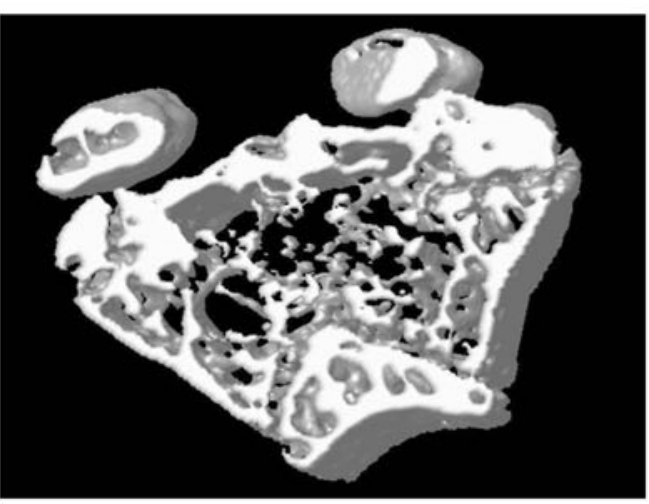

OVX + Vehicle

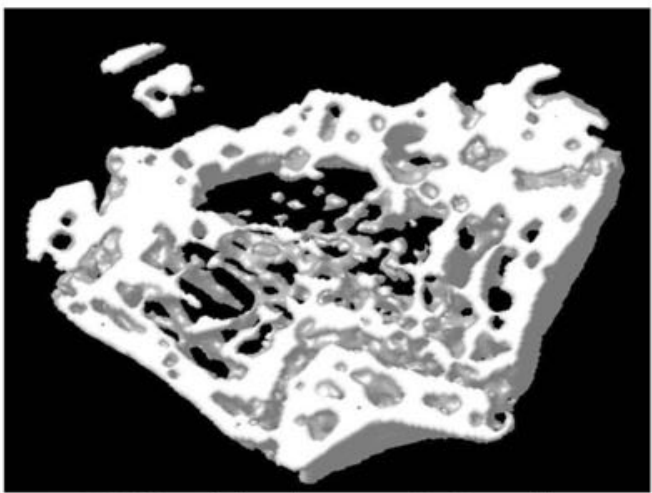

OVX + Alendronate $2.5 \mathrm{mg} / \mathrm{kg}$
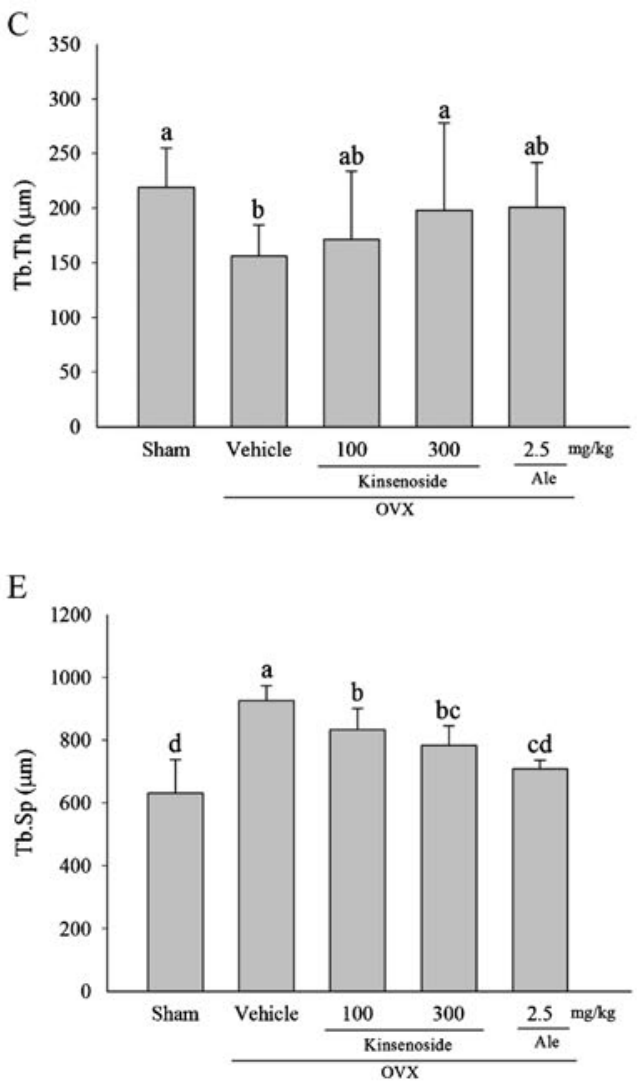
(ANOVA) following the Duncan's test. A $p$ value $<0.05$ was considered statistically significant.

\section{Results}

\section{MicroCT analysis in OVX mice}

Figure 1a shows 3D renderings of the trabecular bone compartment as imaged by micro-computed tomography (microCT). Microtomography scanning showed that trabecular bone volume (38\%; $p<0.05)$, trabecular thickness $(29 \% ; p<$ $0.05)$, and the number of trabeculae $(25 \% ; p<0.05)$ in the distal femoral metaphysis decreased significantly in OVX mice (Fig. 1b-d). In addition, trabecular separation $(42 \% ; p<0.05)$ in the distal femoral metaphysis increased significantly in OVX mice (Fig. 1e). Treating OVX mice with kinsenoside led to a $14 \%(100 \mathrm{mg} / \mathrm{kg} ; p<0.05)$ and $23 \%$ increase $(300$ $\mathrm{mg} / \mathrm{kg} ; p<0.05)$ in trabecular bone volume, a $28 \%$ increase $(300 \mathrm{mg} / \mathrm{kg} ; p<0.05)$ in trabecular thickness, a $13 \%$ $(100 \mathrm{mg} / \mathrm{kg} ; p<0.05)$ and $40 \%$ increase $(300 \mathrm{mg} / \mathrm{kg}$; $p<0.05)$ in the number of trabeculae, and an $8 \%(100 \mathrm{mg} / \mathrm{kg}$; $p<0.05)$ and $15 \%(300 \mathrm{mg} / \mathrm{kg} ; p<0.05)$ decrease in trabecular separation. Treating OVX mice with alendronate produced a $17 \%(p<0.05)$ increase in trabecular bone volume, a $20 \%$ $(p<0.05)$ increase in the number of trabeculae, and a $24 \%$ $(p<0.05)$ decrease in trabecular separation.

Biochemical analysis in OVX mice

Four weeks after the operation, the OVX mice showed significant increases in plasma CTx concentrations $(p<0.05)$ and ALP activities $(p<0.05)$, compared with the sham-operated mice (Fig. 2a). Four weeks after kinsenoside administration, mice in the OVX + vehicle and OVX + kinsenoside groups showed no differences in the plasma level of ALP. The OVX mice receiving kinsenoside $(100$ and $300 \mathrm{mg} / \mathrm{kg} ; p<0.05)$ and alendronate $(2.5 \mathrm{mg} / \mathrm{kg}$ every other day; $p<0.05)$ for 4 weeks had significantly lowered plasma CTx concentration.

\section{Bone histology analysis in OVX mice}

Figure $2 \mathrm{c}$ and $\mathrm{d}$ show that the number of osteoclasts in the region of the primary spongiosa significantly increased in the
A

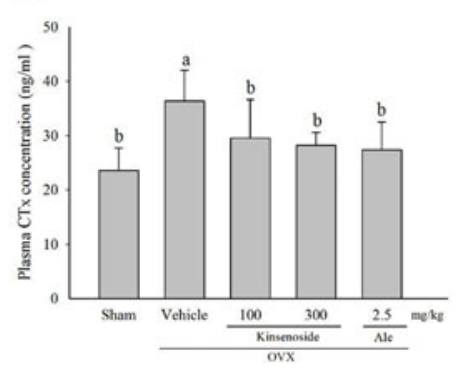

B

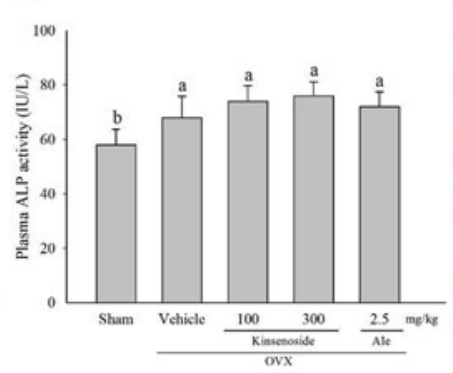

$\mathrm{C}$

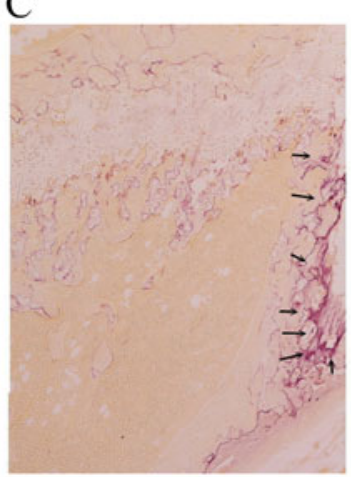

D

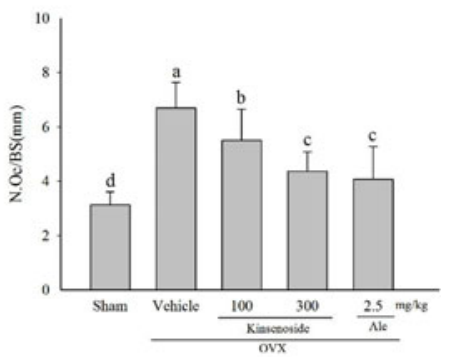

$\mathrm{E}$

OVX

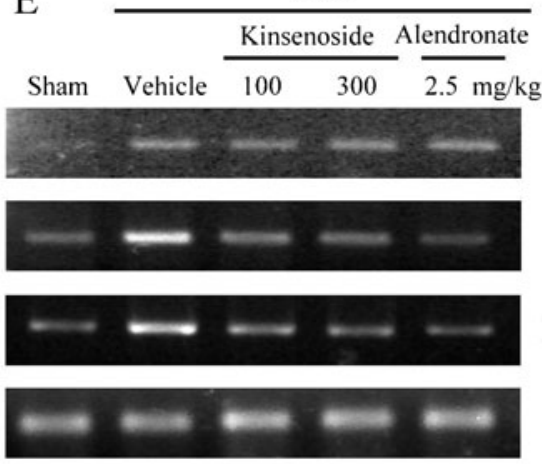

ALP

TRAP

MMP-9

GAPDH

Fig. 2 Biochemical, histological, and RT-PCR analyses on the metaphysis of the distal femur or tibiae in OVX mice. a Effects of kinsenoside on plasma ALP levels in OVX mice. b Effects of kinsenoside on plasma CTx levels in OVX mice. c Photomicrograph of femur section of $\mathrm{OVX}+\mathrm{H}_{2} \mathrm{O}$ group. d Histogram representing the osteoclast number/mm bone surface $(\mathrm{N}$. Oc/BS).



e Fragments were amplified by RT-PCR. f The expression levels of ALP, TRAP, and MMP-9 mRNA were measured and quantified densitometrically. Values were normalized to GAPDH mRNA expression. All values are means $\pm \mathrm{SD}(n=8)$. Values not sharing a common superscript differ significantly. c $100 \times$ 
OVX mice $(p<0.05)$. Kinsenoside (100 and $300 \mathrm{mg} / \mathrm{kg}$ ) and alendronate treatments decreased the number of osteoclasts in OVX mice $(p<0.05)$.

RT-PCR analysis of tibial mRNA expression in OVX mice

The fragments shown in Fig. 2e reflect the pooled data for eight samples. The RT-PCR analysis of the tibial sample in Fig. 2f shows that the expressions of ALP, TRAP, and MMP9 were $168 \%(p<0.05), 157 \%(p<0.05)$, and $220 \%(p<$ $0.05)$ higher in the OVX group than in the sham group. Treatment with kinsenoside led to $23 \%(100 \mathrm{mg} / \mathrm{kg})$ and $32 \%(300 \mathrm{mg} / \mathrm{kg} ; p<0.05)$ decreases in TRAP expression and $27 \%(100 \mathrm{mg} / \mathrm{kg}, p<0.05)$ and $36 \%(300 \mathrm{mg} / \mathrm{kg}$, $p<0.05)$ decreases in MMP-9 expression. Treatment with alendronate led to a $54 \%(p<0.05)$ decrease in TRAP expression and a $41 \%(p<0.05)$ decrease in MMP-9 expression. Kinsenoside and alendronate did not affect ALP mRNA expression.

Kinsenoside inhibited RANKL-induced osteoclastogenesis of BMs and RAW 264.7 cells

Treating BMs with kinsenoside $(10-50 \mu \mathrm{M})$ for 3 days did not affect cell viability, which was assessed by the MTS assay (data not shown). Figure 3a shows that kinsenoside does-dependently inhibited the formation of large TRAPpositive multinucleated osteoclasts in BM cultures in the presence of M-CSF and RANKL. Kinsenoside inhibited osteoclast formation by $17 \%(p<0.05), 26 \%(p<0.05)$, and $50 \%(p<0.05)$ at 10,25 , and $50 \mu \mathrm{M}$, respectively.

Treating RAW 264.7 cells with kinsenoside $(10-50 \mu \mathrm{M})$ for 3 days did not affect cell viability, which was assessed by the MTS assay (data not shown). Figure 3b shows that kinsenoside dose-dependently inhibited RANKL-induced osteoclast differentiation in RAW 364.7 cells. Kinsenoside inhibited osteoclast formation by $20 \%(p<0.05), 60 \%$ $(p<0.05)$, and $71 \%(p<0.05)$ at 10,25 , and $50 \mu \mathrm{M}$, respectively.

Kinsenoside inhibited early-stage osteoclastogenesis

Complete osteoclast differentiation of RAW 264.7 cells takes up to 5 days after RANKL stimulation. To identify which stage of osteoclastogenesis was affected by kinsenoside, RAW 264.7 cells were treated with $50 \mu \mathrm{M}$ of kinsenoside on different days, from Day 0 to Day 4 after RANKL stimulation. Kinsenoside inhibited osteoclast formation by concurrent addition (Day 0 ) or by Day 1 after RANKL stimulation (Fig. 3c and d). When kinsenoside was added to the culture for the final 3 days (Days 2-4), it failed to suppress RANKL-induced osteoclast differentiation. Kinsenoside inhibited osteoclast formation by
$44 \%(p<0.05)$ and $32 \%(p<0.05)$ at Day 0 and Day 1, respectively.

Kinsenoside inhibited bone resorption

RAW264.7 cells were plated on bone slices and stimulated with RANKL in the presence or absence of kinsenoside. RANKL-stimulated cells formed a number of pits (Fig. 3e), indicating that the bone resorption activity of RANKL-treated cells transformed them into functionally active state resembling osteoclasts. Treatment with kinsenoside $(10-50 \mu \mathrm{M})$ significantly reduced the number and area of resorption pits compared with RANKL treatment alone. Kinsenoside inhibited osteoclast resorption by $20 \%(10 \mu \mathrm{M} ; p<0.05)$, $34 \%(25 \mu \mathrm{M} ; p<0.05)$, and $67 \%(50 \mu \mathrm{M} ; p<0.05)$.

Kinsenoside inhibited RANKL-induced NF- $K B$ activation by electrophoretic mobility shift assay

RAW 264.7 cells were pretreated with kinsenoside for $2 \mathrm{~h}$ and then treated with RANKL for $1 \mathrm{~h}$. The prepared nuclear extracts were then assayed for NF- $\mathrm{BB}$ activation by the electrophoretic mobility shift assay (EMSA). Figure $4 \mathrm{a}-\mathrm{c}$ show that RANKL treatment caused a significant increase in the DNA-binding activity of NF-kB $(p<0.05)$. Treating RAW 264.7 cells with kinsenoside (25 and $50 \mu \mathrm{M})$ significantly suppressed the RANKL-induced DNA-binding activity of NF- $\mathrm{KB}$ by $13 \%(p<0.05)$ and $35 \%(p<0.05)$, respectively.

Kinsenoside inhibited RANKL-induced NF- $\mathrm{KB}$ activation by immunofluorescence staining

Figure 4d shows that, in the absence of RANKL, most p65 were located in the cytoplasm. However, nearly all p65 was located in the nucleus after RANKL stimulation. The nuclear translocation of p65 was blocked when incubation occurred with 25 and $50 \mu \mathrm{M}$ kinsenoside combined with RANKL.

Kinsenoside inhibited RANKL-induced NF- $\kappa$ B activation by luciferase assay

The luciferase reporter gene assay in this study shows the effects of kinsenoside on NF-KB activity. RAW 264.7 cells were transiently transfected with an NF-KB-driven luciferase reporter construct. RANKL induced an increase in NF- $\mathrm{KB}$ promoter-driven luciferase gene expression compared to RAW 264.7 cells cultured in a medium without RANKL (Fig. 4e; $p<0.05$ ). Treating RAW 264.7 cells with kinsenoside $(10,25$, and $50 \mu \mathrm{M})$ strongly inhibited RANKL-induced NFKB transcriptional activation by $20 \%(p<0.05), 37 \%(p<$ $0.05)$, and $45 \%(p<0.05)$, respectively. 
A

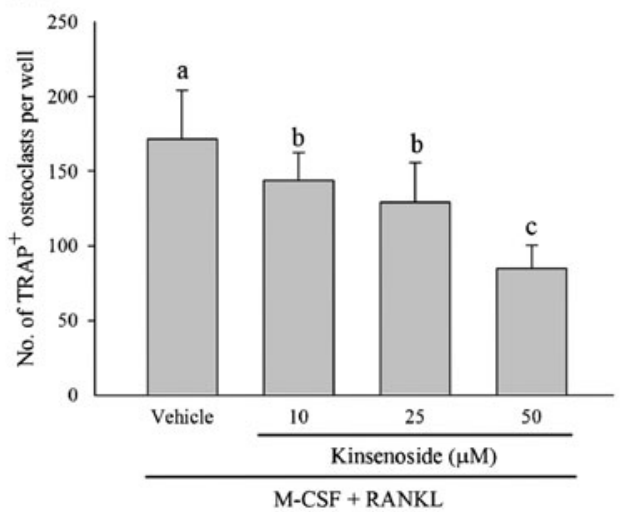

B

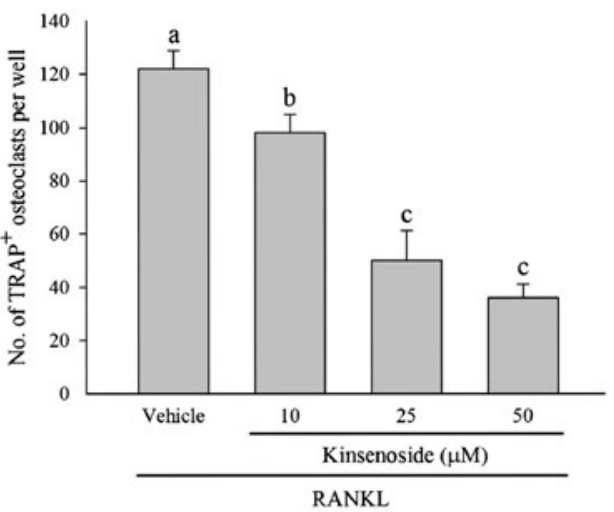

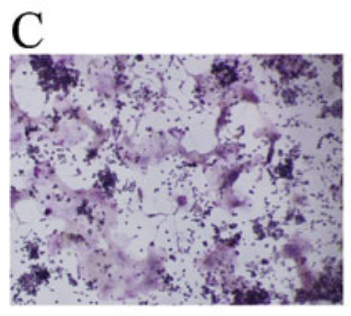

Control

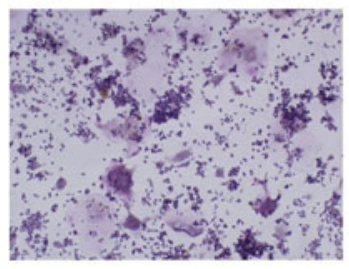

Day 2

$\mathrm{E}$
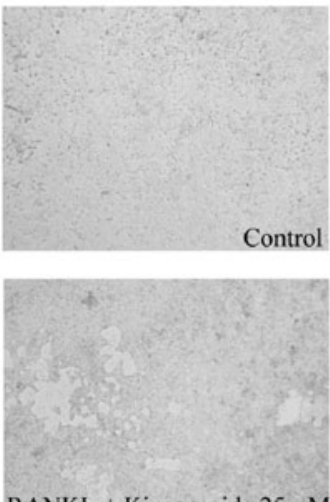

RANKL + Kinsenoside $25 \mu \mathrm{M}$

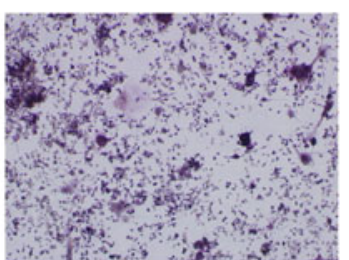

Day 0

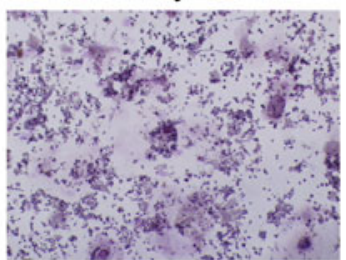

Day 3

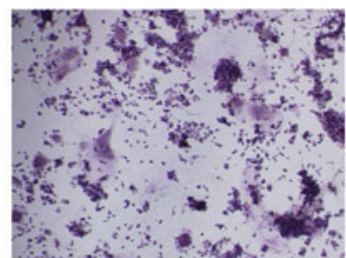

Day 1

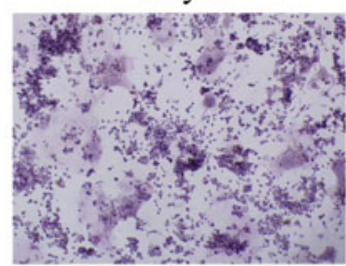

Day 4

$\mathrm{D}$

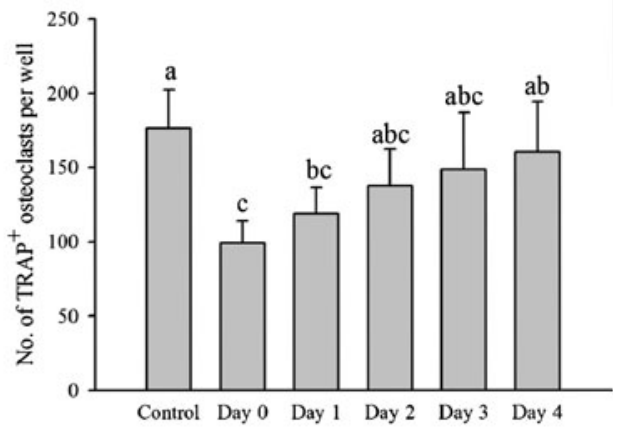

F
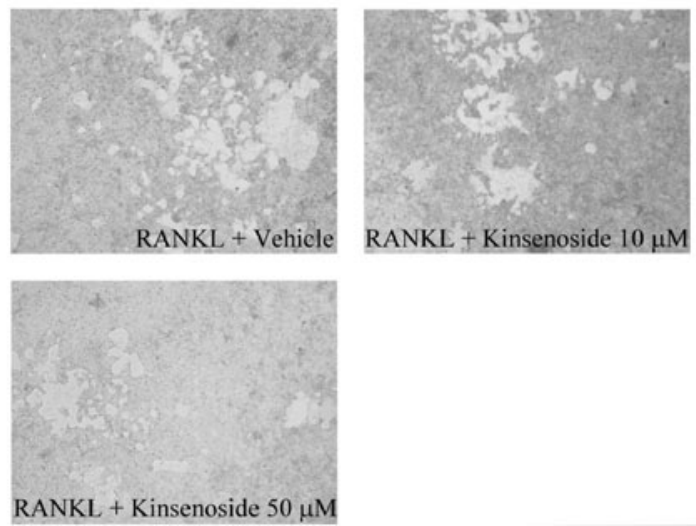

Kinsenoside $10 u \mathrm{M}$

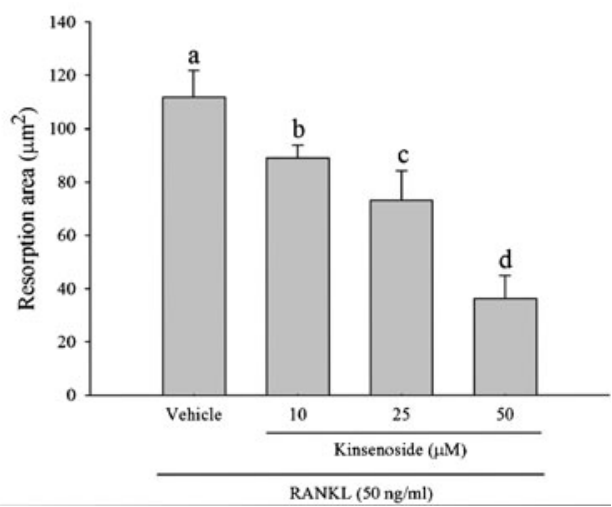

Fig. 3 Kinsenoside inhibited RANKL-induced osteoclastogenesis and bone resorption. a BMs were cultured with the indicated dose of kinsenoside in the presence of M-CSF and RANKL. After 9 days, cells were fixed and stained with TRAP. Multinucleated osteoclasts were counted. b RAW 246.7 cells were cultured with the indicated dose of kinsenoside in the presence of RANKL. After 5 days, cells were fixed and stained with TRAP. Multinucleated osteoclasts were counted. c Kinsenoside inhibited RANKL-induced osteoclastogenesis at an early stage. The TRAP stains of osteoclasts were treated with kinsenoside $(50 \mu \mathrm{m})$ at the same time or after indicated time periods. Cells were cultured for 5 days after RANKL treatment and stained for TRAP expression. Multinucleated osteoclasts were counted. The quantitative data are shown in d. e RAW 246.7 cells plated on BD BioCoat ${ }^{\mathrm{TM}}$ Osteologic ${ }^{\mathrm{TM}}$ and incubated with different concentrations of kinsenoside in the presence of RANKL $(50 \mathrm{ng} / \mathrm{ml})$ for 7 days. Cells were removed by washing with distilled water and resorbed areas were measured. The quantitative data are shown in $\mathbf{f}$. All values are expressed as means $\pm \mathrm{SD}(n=3)$. Values not sharing a common superscript differ significantly. $\mathbf{c} \times 100$ 
A

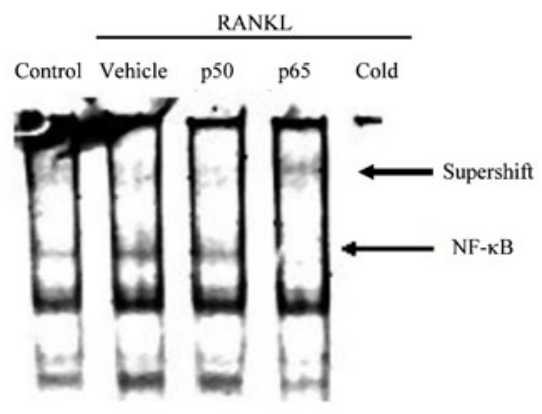

B

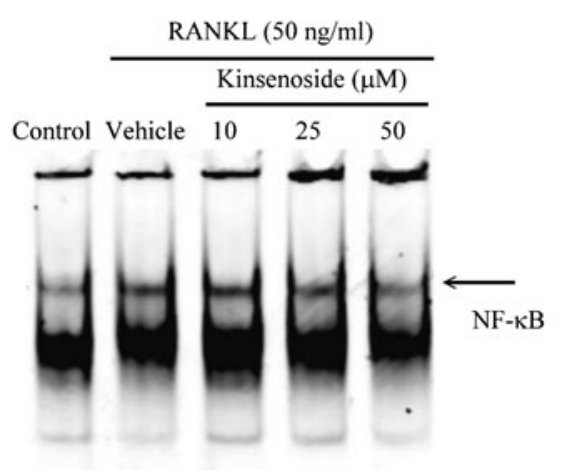

$\mathrm{C}$

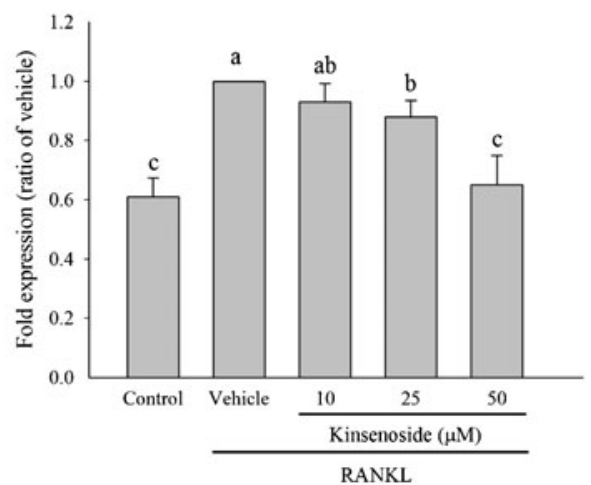

$\mathrm{D}$

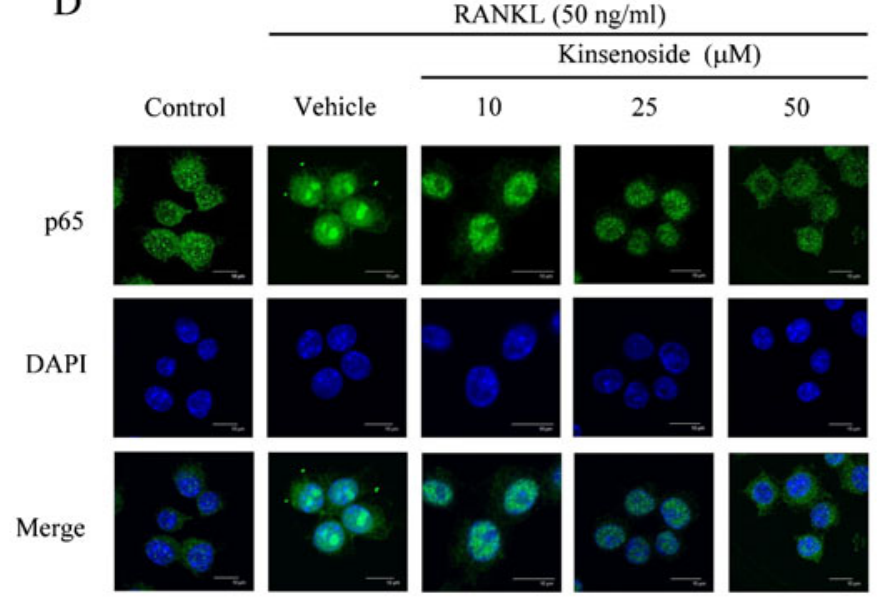

E

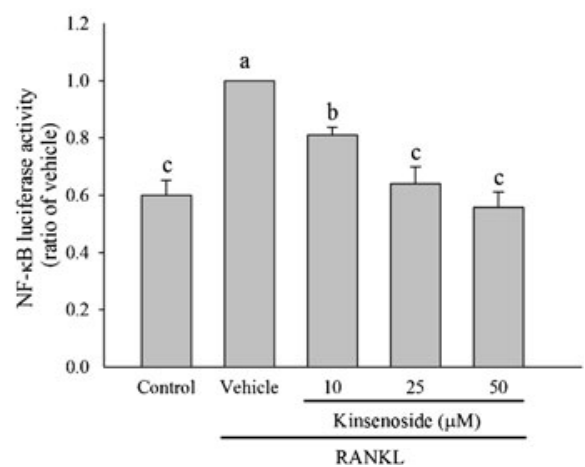

Fig. 4 Kinsenoside inhibited RANKL-induced transcriptional activity of NK- $\mathrm{KB}$ in RAW 264.7 cells. a EMSA results showed a supershift of complex formed in the presence of anti-p50 and anti-p65 antibodies. The $\mathrm{p} 65$ subunits cause a specific binding of NF- $\mathrm{kB}$ to consensus DNA sequence. Cold the nuclear extract was preincubated with an excess of unlabeled oligonucleotide. b RAW 264.7 cells were incubated with or without the indicated concentrations of kinsenoside for $2 \mathrm{~h}$ and then treated with RANKL for $1 \mathrm{~h}$ and tested for nuclear NF- $\mathrm{kB}$ by EMSA. The quantitative data are shown in c. d RAW 264.7 cells were

Effects of kinsenoside on nuclear translocation of p65 and p50 in RANKL-stimulated RAW 264.7 cells

Treatment with RANKL for 60 min caused the translocation of $\mathrm{p} 65$, but not $\mathrm{p} 50$, into the nucleus by Western blot analysis $(p<0.05)$. The nuclear translocation of the $\mathrm{p} 65$ subunit in the RANKL group was 4.2 times greater than that in the control group (Fig. 5a). RAW 264.7 cells were incubated with kinsenoside for $120 \mathrm{~min}$ and then treated with RANKL. Kinsenoside led to a $12 \%(25 \mu \mathrm{M} ; p<0.05)$ and $38 \%(50 \mu \mathrm{M} ; p<$ 0.05 ) decrease in p65 expression (Fig. 5a).

Kinsenoside inhibited NFATc1 expression

RAW 264.7 cells were incubated with RANKL in the presence or absence of kinsenoside for $2 \mathrm{~h}$. Treatment with RANKL for pretreated with kinsenoside and then stimulated with RANKL for $1 \mathrm{~h}$. The localization of $\mathrm{p} 65$ was visualized by immunofluorescence analysis. e RAW 264.7 cells were transiently transfected with an NF$\mathrm{kB}$ promoter plasmid for $16 \mathrm{~h}$. After transfection, the cells were incubated with the indicated concentrations of kinsenoside for $2 \mathrm{~h}$ and then treated with RANKL for an additional $24 \mathrm{~h}$. Cells were lysed, and the luciferase activity was determined by using a luciferase reporter assay system. Values are expressed as means $\pm \mathrm{SD}(n=3)$. Values not sharing a common superscript differ significantly

$24 \mathrm{~h}$ raised the protein expression levels of NFATc1 by Western blot analysis (Fig. $5 \mathrm{~b} ; p<0.05$ ). The expression level of NFATc1 in the RANKL group was 3.5 times greater than that in control group. Pretreatment with kinsenoside led to a $40 \%$ $(25 \mu \mathrm{M} ; p<0.05)$ and $60 \%(50 \mu \mathrm{M} ; p<0.05)$ decrease in NFATc1 expression (Fig. 5b).

Effects of kinsenoside on cytoplasmic phosphorylation levels of $\mathrm{p}-\mathrm{I} \kappa \mathrm{B} \alpha$, p-p65, and $\mathrm{p}-\mathrm{IKK} \alpha / \beta$ in RANKLstimulated RAW 264.7 cells

RAW 264.7 cells were incubated with RANKL in the presence or absence of kinsenoside for $2 \mathrm{~h}$. Treatment with RANKL for $1 \mathrm{~h}$ increased the cytoplasmic phosphorylation levels of $\mathrm{p}$-I $\mathrm{B} \alpha$, p-p 65 , and $\mathrm{p}$-IKK $\alpha / \beta$, but not $\operatorname{I\kappa B} \alpha$, IKK $\alpha$, and $\operatorname{IKK} \beta$, by Western blot analysis (Fig. $5 c$ and d). The 
A
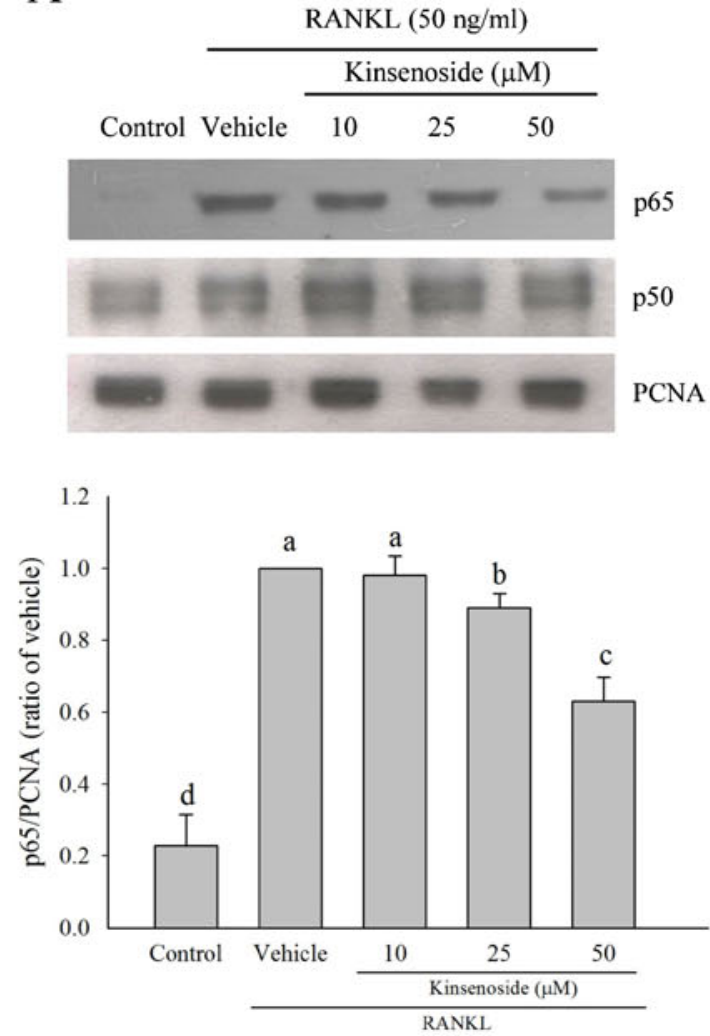

C

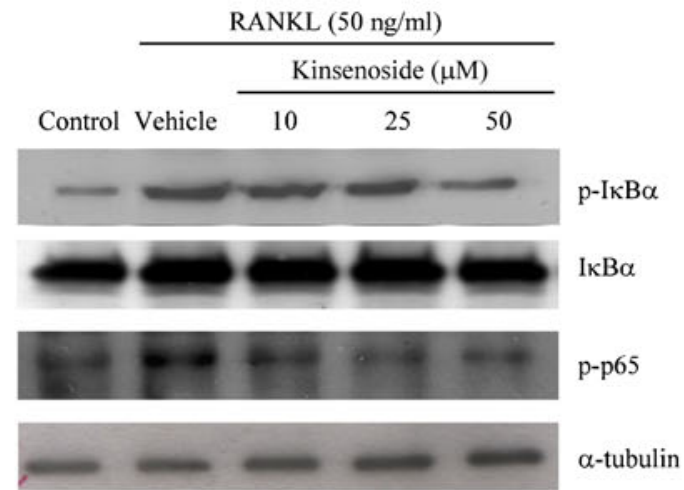

B
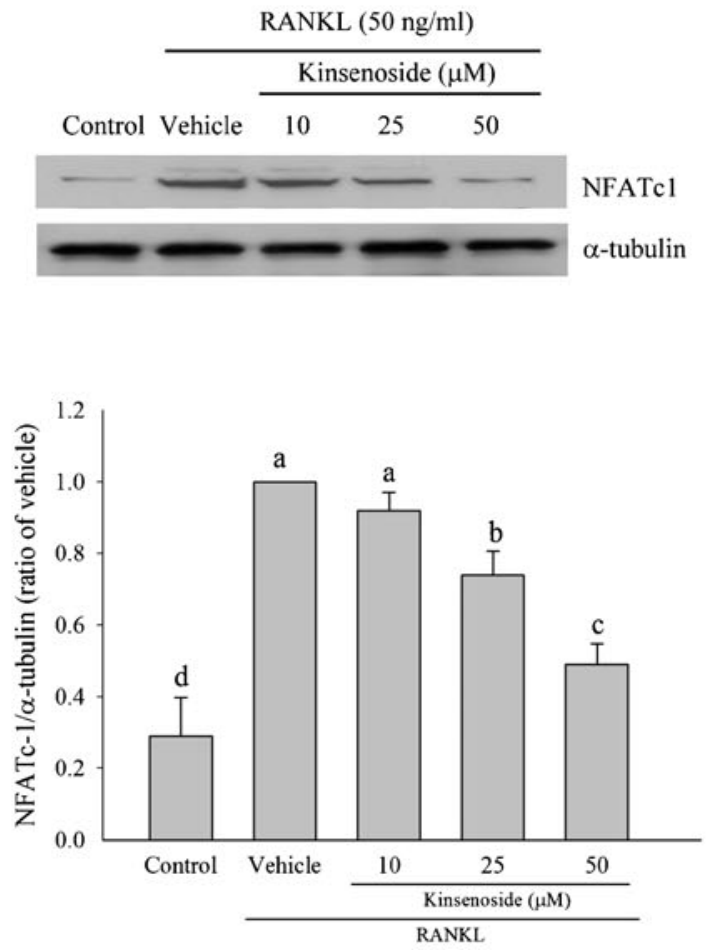

D

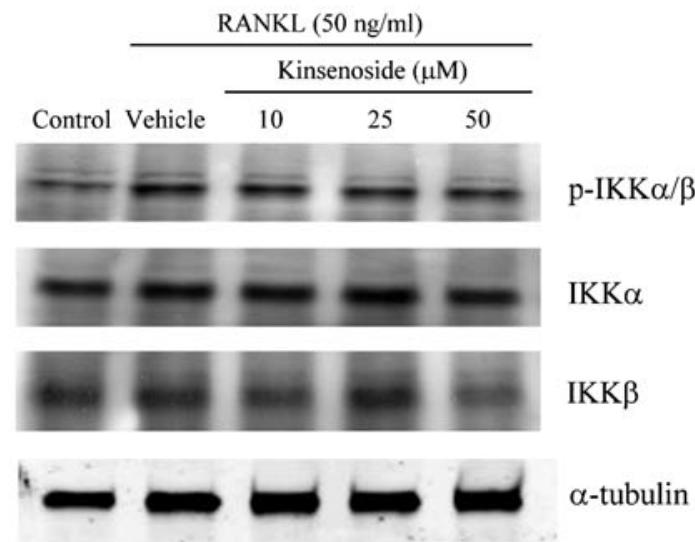

E

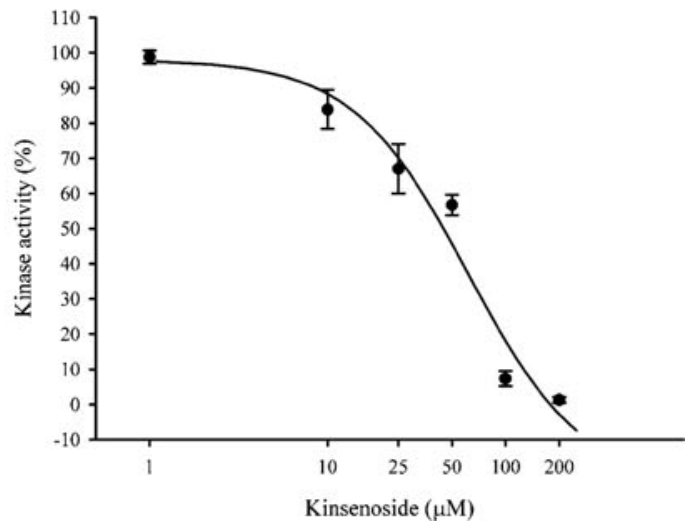


Fig. 5 Western blot analysis and kinase activity assay of IKK $\alpha$. a RAW 264.7 cells were preincubated for $2 \mathrm{~h}$ with indicated concentrations of kinsenoside and then activated for $1 \mathrm{~h}$ with RANKL. Nuclear fractions were obtained for the detection of p65 and p50 levels. b RAW 264.7 cells were preincubated for $2 \mathrm{~h}$ with indicated concentrations of kinsenoside and then activated for $24 \mathrm{~h}$ with RANKL. The whole proteins were obtained for the detection of NFATc1 levels. c Cytoplasmic fractions were obtained for the detection of $\mathrm{p}$-I $\operatorname{IK} \mathrm{B} \alpha, \operatorname{I\kappa } B \alpha$, and p-p65 levels. d Cytoplasmic fractions were obtained for the detection of IKK $\alpha, \operatorname{IKK} \beta$, and $\mathrm{p}$-IKK $\alpha / \beta$ levels. All values are expressed as means $\pm \operatorname{SD}(n=3)$. Values not sharing a common superscript differ significantly. e In vitro kinase assay of IKK was done as described in "Materials and methods". The IC50 values were approximately $57.6 \mu \mathrm{M}$. Values were expressed as means $\pm \mathrm{SD}(n=3)$

phosphorylation levels of $\mathrm{p}-\mathrm{I} \kappa \mathrm{B} \alpha$ and $\mathrm{p}$-p65 in the RANKL group were $182 \%(p<0.01)$ and $182 \%(p<0.05)$, respectively, both of which were greater than those in the control group. Kinsenoside treatment did not affect the level of IKB $\alpha$. Kinsenoside treatment led to $27 \%(25 \mu \mathrm{M} ; p<0.05)$ and $39 \%$ (50 $\mu \mathrm{M} ; p<0.05)$ decreases in $\mathrm{p}$-I $\mathrm{KB} \alpha$ level and $16 \%$ $(10 \mu \mathrm{M} ; p<0.05), 32 \%(25 \mu \mathrm{M} ; p<0.05)$, and $39 \%$ $(50 \mu \mathrm{M} ; p<0.05)$ decrease in p-p65 level (Fig. $5 \mathrm{c})$.

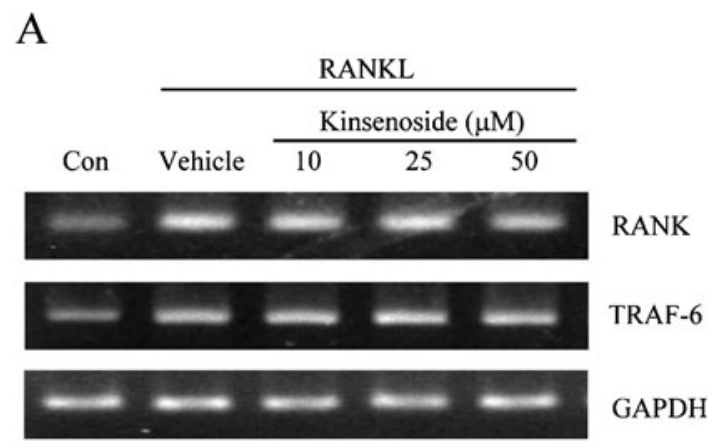

C

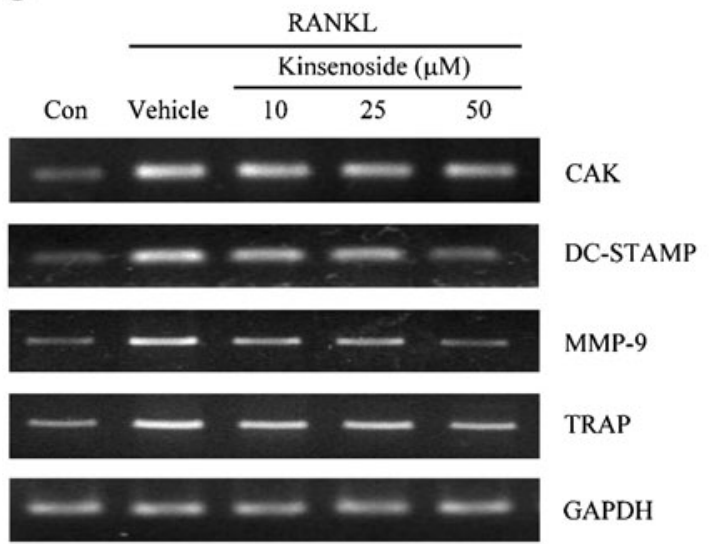

Fig. 6 Effects of kinsenoside on expression of RANKL-regulated genes. a BMs were preincubated for $2 \mathrm{~h}$ with indicated concentrations of kinsenoside and then activated for $24 \mathrm{~h}$ with RANKL. RANK and TRAF6 mRNAs were amplified by RT-PCR. b Total RNA from BMs was isolated on the indicated days after RANKL incubation, and mRNA expression of TRAP, DC-STAMP, CAK, and MMP-9 was
The levels of $\mathrm{p}-\mathrm{IKK} \alpha / \beta$ in the RANKL group were $145 \%(p<0.05)$ greater than that in the control group. Kinsenoside treatment did not affect the levels of IKK $\alpha$, $\operatorname{IKK} \beta$, and p-IKK $\alpha / \beta$ (Fig. 5d).

Kinsenoside inhibited IKK activity

To determine whether kinsenoside interacts with IKK directly, this study examines the effects of kinsenoside on IKK enzymatic activity. The culture treatment of RAW 264.7 cells with $50 \mathrm{ng} / \mathrm{ml}$ RANKL for $1 \mathrm{~h}$ effectively increased IKK activity. Kinsenoside treatment (10-200 $\mu \mathrm{M})$ for $2 \mathrm{~h}$ inhibited IKK activity in a concentration-dependent manner. The IC50 value was approximately 57.6 $\mu \mathrm{M}$ (Fig. 5e).

Kinsenoside did not affect the mRNA expression of RANK and TRAF6

The fragments shown in Fig. 6a reflect the pooled data for three samples. The BMs were incubated with M-CSF

\section{B}

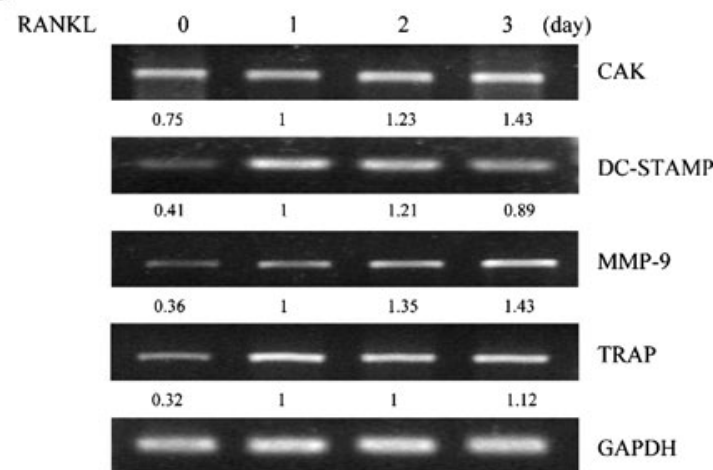

D

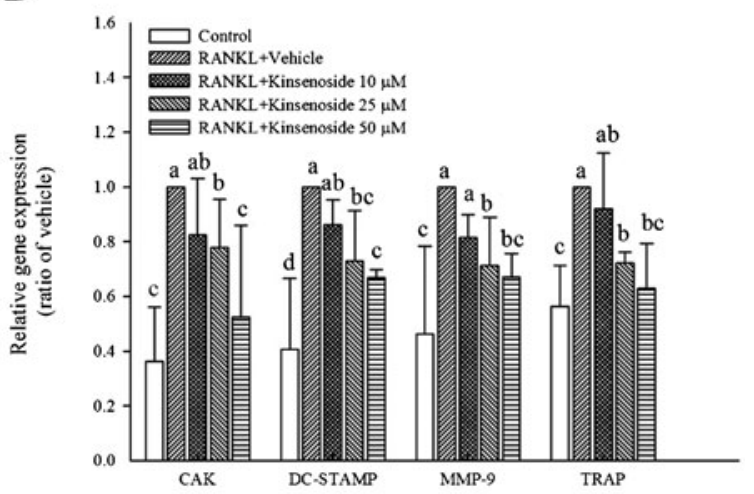

analyzed by RT-PCR. $\mathbf{c}$ BMs were preincubated for $2 \mathrm{~h}$ with indicated concentrations of kinsenoside and then activated for $24 \mathrm{~h}$ with RANKL. TRAP, DC-STAMP, CAK, and MMP-9 mRNAs were amplified by RT-PCR. The quantitative data are shown in $\mathbf{d}$. Values are mean $\pm \mathrm{SD}(n=3) .{ }^{\# \#}<<0.01$ as compared with the control group. Values not sharing a common superscript differ significantly 
(20 $\mathrm{ng} / \mathrm{ml}$ ) for 3 days to induce the production of osteoclast precursor. Osteoclast precursors incubated with kinsenoside for $120 \mathrm{~min}$ were then treated with M-CSF $(20 \mathrm{ng} / \mathrm{ml})$ and RANKL $(50 \mathrm{ng} / \mathrm{ml})$ for 1 day in the presence or absence of kinsenoside. As Fig. 6a shows, RT-PCR amplified fragments of RANK and TRAF6. The RANK/GAPDH and TRAF6/GAPDH ratios in the RANKL group were $170 \%$ $(p<0.05)$ and $220 \%(p<0.05)$, respectively, both of which are greater than those in the control group. Kinsenoside treatment $(10-50 \mu \mathrm{M})$ did not affect the ratios of RANK/ GAPDH and TRAF6/GAPDH (Fig. 6a).

Kinsenoside inhibited the mRNA expression of CAK, DC-STAMP, MMP-9, and TRAP

The osteoclast fusion and resorption-related gene were activated lately. To confirm the RANKL-induced expression of these genes, mRNA was extracted 24, 48, and $72 \mathrm{~h}$ after RANKL challenge for RT-PCR analysis. Figure $6 \mathrm{~b}$ shows that all TRAP/ GAPDH, DC-STAMP/GAPDH, MMP-9/GAPDH, and CAK/ GAPDH ratios in the 24-72 $\mathrm{h}$ after RANKL treatments were greater than those in the control group. Therefore, mRNA from BMs challenged with RANKL for $24 \mathrm{~h}$ was used to examine the effects of kinsenoside. Figure $6 \mathrm{c}$ and $\mathrm{d}$ show that kinsenoside treatment $(10-50 \mu \mathrm{M})$ led to $22 \%(25 \mu \mathrm{M} ; p<0.05)$ and $48 \%(50 \mu \mathrm{M} ; p<0.05)$ decreases in CAK expression, $27 \%$ $(25 \mu \mathrm{M} ; p<0.05)$ and $33 \%(50 \mu \mathrm{M} ; p<0.05)$ decreases in DCSTAMP expression, $28 \%(25 \mu \mathrm{M} ; p<0.05)$ and $33 \%(50 \mu \mathrm{M}$; $p<0.05)$ decreases in MMP-9 expression, and $28 \%(25 \mu \mathrm{M}$; $p<0.05)$ and $37 \%(50 \mu \mathrm{M} ; p<0.05)$ decreases in TRAP expression.

\section{Discussion}

In the present study, kinsenoside ameliorated OVX-induced osteopenia in mice, through the inhibition of osteoclatogenesis. The in vitro study also indicates that kinsenoside inhibits osteoclastogenesis from BMs and RAW 264.7 cells.

This study used a mouse model to evaluate the efficacy of kinsenoside in the treatment of postmenopausal osteoporosis. Microtomographic scanning shows a decrease in trabecular bone volume, thickness, and the number of trabeculae, with an increase in the trabecular separation of the metaphysis of the femur in the OVX mice. Treatment with kinsenoside significantly reduced this bone loss in the OVX mice.

The plasma activity of ALP, an index of bone formation [4], was reported to be significantly greater in an OVX group than in a sham-operated group [4]. A similar change was observed in the present study. Kinsenoside treatment did not influence the activity of plasma ALP. CTx is a marker of bone resorption [4], and OVX increases the content of CTx in the plasma; however, this effect was decreased through treatment with kinsenoside. These results suggest that kinsenoside ameliorated bone loss induced by OVX by inhibiting bone resorption as opposed to enhancing bone formation. In the present study, kinsenoside ameliorated OVX-induced osteopenia in mice through the inhibition of osteoclatogenesis. The in vitro study also indicates that kinsenoside inhibits osteoclastogenesis from BMs and RAW 264.7 cells.

Osteoclasts are multinucleated cells of hematopoietic origin and are the primary bone-resorbing cells [5]. TRAP is a different form of the enzyme acid phosphatase, which is found mainly in bone. Osteoclasts release TRAP during bone resorption [21]. Histological sections stained with TRAP showed that the number of osteoclasts decreased in the region of the spongiosa in kinsenoside-treated OVX mice. TRAP activity is commonly used as a histochemical marker of identifying osteoclasts [26]. MMP-9 is required for osteoclastic migration and resorption [27]. Kinsenoside treatment inhibited the mRNA expression of femoral TRAP and $M M P-9$, but not $A L P$. These findings indicate that kinsenoside can suppress the differentiation and resorption of osteoclasts. These results agree with the findings obtained by Masuda et al., who showed that the ethanolic extract of A. formosanus inhibited bone loss caused by OVX by suppressing osteoclast formation [18].

Osteoclasts are multinucleated cells originating from the fusion of mononuclear progenitors in the monocyte/macrophage family [28]. Previous research has shown that two key molecules, M-CSF and RANKL, are essential and sufficient to promote osteoclastogenesis [8]. Thus, M-CSF and RANKL were added to induce osteoclastogenesis in the primary BM cell culture system. In the RAW 264.7 macrophage cell-cultured system, only RANKL was added to induce osteoclast differentiation. In this study, kinsenoside dose-dependently suppressed the formation of osteoclasts in BMs and a RAW 264.7 cell culture system. Results further show that RAW 264.7 cells were markedly blocked by the concurrent administration of RANKL and kinsenoside and weakly blocked by subsequent addition of kinsenoside. This suggests that inhibition occurred during the initial stage of osteoclastogenesis.

Previous research has shown that M-CSF enhances RANKL-induced osteoclast formation [29]. To exclude the interference of M-CSF, therefore, RANKL-induced RAW 264.7 cell differentiation into osteoclastlike cells was used to assess the effects of kinsenoside on the signal transduction pathway. In addition, a BM system was used to examine the effects of kinsenoside on osteoclast precursor fusion, osteoclast formation, and resorption.

Activation of the NF- $\mathrm{kB}$ pathway is a key factor in RANKL-induced osteoclast differentiation [10]. The results of EMSA analysis show that kinsenoside inhibits the 
RANKL-induced DNA binding activity of p65. Immunofluorescence staining and Western blot analysis of nuclear protein also show that kinsenoside suppressed the nuclear translocation of $\mathrm{p} 65$ protein. Using transient transfection with $\mathrm{\kappa B}$-luciferase as an indicator of NF- $\mathrm{kB}$ activity, this study shows that kinsenoside inhibits the RANKL-increased NF- $K B$ activity. These results clearly show that the antiosteoclastogenic effects of kinsenoside may occur through the inhibition of NF-KB signaling.

RANK lacks intrinsic enzymatic activity in its intracellular domain, and it transduces signaling by recruiting adaptor molecules such as the TRAF family of proteins [8]. Genetic experiments show that TRAF6 is required for osteoclast formation and osteoclast activation [30]. The binding of RANKL to its receptor RANK recruits TRAF6 and subsequently initiates a kinase cascade. RT-PCR analysis shows that kinsenoside did not reduce the RANKL-induced mRNA expression of $R A N K$ and TRAF-6, indicating that kinsenoside inhibits NF- $\mathrm{KB}$ activation through downstream kinase to TRAF6.

The classical NF- $\mathrm{kB}$ signaling pathway involves the activation of the IKK complex, which phosphorylates I $\mathrm{K} B \alpha$ and targets them for ubiquitin-dependent degradation [8]. In the alternative IKB-independent pathway, direct phosphorylation of NF- $\mathrm{KB}$ subunit $\mathrm{p} 65$ by IKK also modulates NF-KB transcription activity [31]. In this study, kinsenoside inhibited RANKL-induced NF-KB activation in RAW 264.7 cells by inhibiting $\mathrm{p}-\mathrm{I} \kappa \mathrm{B} \alpha$ and $\mathrm{p}-\mathrm{p} 65$. This indicates that kinsenoside inhibited NF-kB translocation through both IкB $\alpha$-dependent and $\mathrm{I} \kappa \mathrm{B} \alpha$-independent pathways.

IKK is the major upstream kinase of $I \kappa B \alpha$ in the NF-kB signaling pathway. In this study, kinsenoside did not inhibit IKK phosphorylation but suppressed the phosphorylation of $\mathrm{I} \kappa \mathrm{B} \alpha$ and $\mathrm{p} 65$. Therefore, this study also investigates the effects of kinsenoside on IKK activity. Results show that kinsenoside significantly inhibits RANKL induction of IKK activity, suggesting that IKK is a critical target for kinsenoside in inhibiting RANKL-induced osteoclastogenesis.

NFATc1 is likely a key regulator of RANKL-induced osteoclast differentiation, fusion, and activation [10]. NF$\mathrm{KB}$ is important for the initial induction of NFATc1. The binding of NF-KB to the NFATCl promoter region induces $N F A T c 1$ gene expression, allowing NFATc1 to autoamplify its expression by binding to its own promoter. This, in turn, leads to the robust induction of NFATc1 during RANKLinduced osteoclast differentiation [32]. In this study, kinsenoside significantly suppressed RANKL-induced NF-KB translocation and NFATc1 nuclear transport.

NFATc1 promotes the expression of osteoclast-specific genes such as TRAP, DC-STAMP, CAK, and MMP-9 [33-35]. In addition to histochemical marker for osteoclasts, TRAP also regulates bone resorption by mediating the degradation of endocytosed matrix products during transcytosis in activated osteoclasts [36]. DC-STAMP, a putative seven- transmembrane spanning protein, is essential for the cellcell fusion of osteoclasts [37]. Proteinases are necessary for bone resorption. Delaisse et al. showed that $C A K$ and $M M P$ 9 are key proteinases in the bone resorption processes [38]. The RT-PCR analysis in this study shows that kinsenoside dose-dependently suppressed the mRNA expression of TRAP, DC-STAMP, CAK, and MMP-9. Thus, kinsenoside, which downregulates NF- $\mathrm{kB}$ and NFATc1 activities, caused substantial inhibition of osteoclast differentiation, fusion, and resorption mediated by RANKL.

This study shows that kinsenoside reduces osteoporosis induced by OVX in mice. Second, kinsenoside has the potential to inhibit the formation of osteoclasts by inhibiting IKK activity, which might influence the activation of NF- $\mathrm{KB}$ and NFAcT1. Third, kinsenoside may suppress the bone resorption activity of mature osteoclasts by regulating the expression of osteoclast fusion-related and resorption-related genes.

Many synthetic agents, such as bisphosphonates and raloxifene, have been developed to treat osteoporosis. However, these drugs are associated with side effects such as dyspepsia and breast cancer. Thus, scientists are pursuing the development of natural products. This study investigates the efficacy of kinsenoside in treating osteoporosis. Recently, we also found that A. formosanus contains prebiotic polysaccharides that could reduce the osteopenia induced by OVX in rats by increasing the concentration of cecal short chain fatty acids (SCFA) [39]. Butyric acid, an SCFA, can stimulate the formation of osteoblasts $[40,41]$. Therefore, it is possible that the extract of A. formosanus may ameliorate bone loss caused by OVX by stimulating bone formation and inhibiting bone resorption [19]. This study proposes the possibility of using $A$. formosanus in the development of therapeutic drugs for osteoporosis.

Acknowledgments This study was supported by grants from the China Medical University (CMU 99-S-15).

Conflicts of interest None.

Open Access This article is distributed under the terms of the Creative Commons Attribution Noncommercial License which permits any noncommercial use, distribution, and reproduction in any medium, provided the original author(s) and the source are credited.

\section{References}

1. Matsuo K (2009) Cross-talk among bone cells. Curr Opin Nephrol Hypertens 18:292-297

2. Teitelbaum SL (2000) Bone resorption by osteoclasts. Science 289:1504-1508

3. Jee WSS, Yao W (2001) Overview: animal models of osteopenia and osteoporosis. J Musculoskel Neuron Interact 1:193-207

4. Yoon KH, Cho DC, Yu SH, Kim KT, Jeon Y, Sung JK (2012) The change of bone metabolism in ovariectomized rats: analyses of 
microCT scan and biochemical markers of bone turnover. J Korean Neurosurg Soc 51:323-327

5. Wada T, Nakashima T, Hiroshi N, Penninger JM (2006) RANKLRANK signaling in osteoclastogenesis and bone disease. Trends Mol Med 12:17-25

6. Galibert L, Tometsko ME, Anderson DM, Cosman D, Dougall WC (1998) The involvement of multiple tumor necrosis factor receptor (TNFR)-associated factors in the signaling mechanisms of receptor activator of NF-kappaB, a member of the TNFR superfamily. J Biol Chem 273:34120-34127

7. Darnay BG, Ni J, Moore PA, Aggarwal BB (1999) Activation of NF-kappaB by RANK requires tumor necrosis factor receptorassociated factor (TRAF) 6 and NF-kappaB-inducing kinase. Identification of a novel TRAF6 interaction motif. J Biol Chem 274:7724-7731

8. Asagiri M, Takayanagi H (2007) The molecular understanding of osteoclast differentiation. Bone 40:251-264

9. Takayanagi H, Kim S, Koga T, Nishina H, Isshiki M, Yoshida $H$ (2002) Induction and activation of the transcription factor NFATc1 (NFAT2) integrate RANKL signaling in terminal differentiation of osteoclasts. Dev Cell 3:889-901

10. Zhao Q, Wang X, Liu Y, He Y, Jia R (2010) NFATc1: functions in osteoclasts. Int J Biochem Cell Biol 42:546-579

11. Eslami B, Zhou S, Van Eekeren I, Leboff MS, Glowacki J (2011) Reduced osteoclastogenesis and RANKL expression in marrow from taking alendronate. Calcif Tissue Int 88:272-280

12. Silverman SL, Landesberg R (2009) Osteonecrosis of the jaw and the role of bisphosphonates: a critical review. Am J Med 22:S33-S45

13. Imai K, Yamamoto S, Anamizu Y, Horiuchi T (2007) Plevic insufficiency fracture associated with severe suppression of bone turnover by alendronate therapy. J Bone Miner Metab 25:333-336

14. Du XM, Irino N, Furusho N, Hayashi J, Shoyama Y (2008) Pharmacologically active compounds in the Anoectochilus and Goodyera species. J Nat Med 62:132-148

15. Wu JB, Lin WL, Hsieh CC, Ho HY, Tsay HS, Lin WC (2007) The hepatoprotective activity of kinsenoside from Anoectochilus formosanus. Phytother Res 21:58-61

16. Zhang Y, Cai J, Ruan H, Pi H, Wu J (2007) Antihyperglycemic activity of kinsenoside, a high yielding constituent from Anoectochilus roxburghii in streptozotocin diabetic rats. J Ethnopharmacol 114:141-145

17. Hsiao HB, Wu JB, Lin H, Lin WC (2011) Kinsenoside isolated from Anoectochilus formosanus suppresses lipopolysaccharidestimulated inflammatory reactions in macrophages and endotoxin shock in mice. Shock 35:184-190

18. Masuda K, Ikeuchi M, Koyama T, Yamaguchi K, Woo JT, Nishimura T (2008) Suppressive effects of Anoectochilus formosanus extract on osteoclast formation in vitro and bone resorption in vivo. J Bone Miner Metab 26:123-129

19. Shih CC, Wu YW, Lin WC (2001) Ameliorative effects of Anoectochilus fromosanus extract on osteopenia in ovariectomized rats. J Ethnopharmacol 77:233-238

20. Bouxsein M, Boyd SK, Christiansen BA, Guldberg RE, Jepsen KJ, Muller R (2010) Guidelines for assessment of bone microstructure in rodents using micro-computed tomography. J Bone Miner Res 25:1468-1486

21. Cole AA, Walters LM (1987) Tartrate-resistant acid phosphatase in bone and cartilage following decalcification and cold-embedding in plastic. J Histochem Cyrochem 35:203-206

22. Asagiri M, Takayanagi $\mathrm{H}$ (2007) The molecular understanding of osteoclast differentiation. Bone 40:251-264

23. Chen CC, Wang JK, Lin SB (1998) Antisense oligonucleotides targeting protein kinase $\mathrm{C}$-alpha, -beta $\mathrm{I}$, or -delta but not -eta inhibit lipopolysaccharide-induced nitric oxide synthase expression in RAW 264.7 macrophages: involvement of a nuclear factor kappa B-dependent mechanism. J Immunol 161:6206-6214
24. Ang E, Liu Q, Qi M, Liu HG, Yang X, Chen H, Zheng MH, Xu J (2011) Mangiferin attenuates osteoclastogenesis, bone resorption, and RANKL-induced activation of NF- $\mathrm{KB}$ and ERK. J Cell Biochem 112:89-97

25. Lee JH, Jin H, Shim HE, Kim HN, Ha H, Lee ZH (2010) Epigallocatechin-3-gallate inhibits osteoclastogenesis by downregulating c-Fos expression and suppressing the nuclear factorkappaB signal. Mol Pharmacol 77:17-25

26. Walsh NC, Cahill M, Carninci P, Kawai J, Okazaki Y, Hayashizaki Y (2003) Multiple tissue-specific promoters control expression of the murine tartrate-resistant acid phosphatase gene. Gene 307:111-123

27. Delaissé JM, Engsig MT, Everts V, del Carmen OM, Ferreras M, Lund L (2000) Proteinases in bone resorption: obvious and less obvious roles. Clin Chim Acta 291:223-234

28. Udagawa N, Takahashi N, Akatsu T, Tanaka H, Sasaki T, Nishihara T (1990) Origin of osteoclasts: mature monocytes and macrophages are capable of differentiating into osteoclasts under a suitable microenvironment prepared by bone marrow-derived stromal cells. Proc Natl Acad Sci USA 87:7260-7264

29. Islam S, Hassan F, Tumurkhuu G, Dagvadorj J, Koide N, Naiki Y, Yoshida T, Yokochi T (2008) Receptor activator of nuclear factorkappa B ligand induces osteoclast formation in RAW 264.7 macrophage cells via augmented production of macrophage-colonystimulating factor. Micrbiol Immunol 52:585-590

30. Lomaga MA, Yeh WC, Sarosi I, Duncan GS, Furlonger C, Ho A (1999) TRAF6 deficiency results in osteoporosis and defective interleukin-1, CD40, and LPS signaling. Genes Dev 13:1015-1024

31. Sakurai H, Chiba H, Miyoshi H, Sugita T, Yoriumi W (1999) IkB kinases phosphorylated NF-kB p65 subunit on serine 536 in the trasactivation domain. J Biol Chem 274:30353-30356

32. Asagiri M, Sato K, Usami T, Ochi S, Nishina H, Yoshida H, Morita I, Wagner EF, Mak TW, Serfling E, Takayanagi H (2005) Autoamplification of NFATc1 expression determines its essential role in bone homeostasis. J Exp Med 202:1261-1269

33. Kim K, Lee SH, Ha Kim J, Choi Y, Kim N (2008) NFATc1 induces osteoclast fusion via up-regulation of Atp6v0d2 and the dendritic cell-specific transmembrane protein (DC-STAMP). Mol Endocrinol 22:176-185

34. Song I, Kim JH, Kim K, Jin HM, Youn BU, Kim N (2009) Regulatory mechanism of NFATc1 in RANKL-induced osteoclast activation. FEBS Lett 583:2435-2440

35. Yu M, Moreno JL, Stains JP, Keegan AD (2009) Complex regulation of tartrate-resistant acid phosphatase (TRAP) expression by interleukin 4 (IL-4): IL-4 indirectly suppresses receptor activator of NFkappaB ligand (RANKL)-mediated TRAP expression but modestly induces its expression directly. J Biol Chem 284:32968-32979

36. Halleen JM, Räisänen S, Salo JJ, Reddy SV, Roodman GD, Hentunen TA, Lehenkari PP, Kaija H, Vihko P, Väänänen HK (1999) Intracellular fragmentation of bone resorption products by reactive oxygen species generated by osteoclastic tartrate-resistant acid phosphatase. J Biol Chem 74:22907-22910

37. Yagi M, Miyamoto T, Sawatani Y, Iwamoto K, Hosogane N, Fujita N (2005) DC-STAMP is essential for cell-cell fusion in osteoclasts and foreign body giant cells. J Exp Med 202:345-351

38. Delaissé JM, Engsig MT, Everts V, del Carmen OM, Ferreras M, Lund L (2000) Proteinases in bone resorption: obvious and less obvious roles. Clin Chim Acta 291:223-234

39. Yang LC, Wu JB, Lu TJ, Lin WC. The prebiotic effect of Anoectochilus formosanus and its consequences on bone health. Brit J Nutr (in press)

40. Katono T, Kawato T, Tanabe N, Suzuki N, Iida T, Morozumi A (2008) Sodium butyrate stimulates mineralized nodule formation and osteoprotegerin expression by human osteoblasts. Arch Oral Biol 53:903-509

41. Schroeder TM, Westendorf J (2005) Histone deacetylase inhibitors promote osteoblast maturation. J Bone Miner Res 20:2254-2263 